\title{
Hyperinsulinism and Hyperammonemia Syndrome: Report of Twelve Unrelated Patients
}

\author{
PASCALE DE LONLAY, CHANTAL BENELLI, FRANÇOISE FOUQUE, ARUPA GANGULY, \\ BERNARD ARAL, CARLO DIONISI-VICI, GUY TOUATI, CLAIRE HEINRICHS, DANIEL RABIER, \\ PIERRE KAMOUN, JEAN-JACQUES ROBERT, CHARLES STANLEY, AND \\ JEAN-MARIE SAUDUBRAY \\ Departments of Pediatrics [P.d.L., G.T., J.-J.R., J.-M.S.], INSERM Unité 30 [C.B., F.F.], and \\ Biochemistry [B.A., D.R., P.K.], Hôpital Necker-Enfants malades, Paris, France; Department of \\ Pediatrics, Hôpital des Enfants Reine Fabiola, Brussels, Belgium [C.H.]; Department of Metabolism, \\ Ospedale Bambino Gesu, Roma, Italy [C.D.-V.]; and Endocrine Division, Children's Hospital, \\ Philadelphia, Pennsylvania [A.G., C.S.]
} \begin{abstract}
Hyperinsulinism and hyperammonemia syndrome has been
reported as a cause of moderately severe hyperinsulinism with diffuse involvement of the pancreas. The disorder is caused by gain of function mutations in the GLUD1 gene, resulting in a decreased inhibitory effect of guanosine triphosphate on the glutamate dehydrogenase (GDH) enzyme. Twelve unrelated patients (six males, six females) with hyperinsulinism and hyperammonemia syndrome have been investigated. The phenotypes were clinically heterogeneous, with neonatal and infancy-onset hypoglycemia and variable responsiveness to medical (diazoxide) and dietary (leucine-restricted diet) treatment. Hyperammonemia $(90-200 \mu \mathrm{mol} / \mathrm{L}$, normal $<50 \mu \mathrm{mol} / \mathrm{L})$ was constant and not influenced by oral protein, by protein- and leucinerestricted diet, or by sodium benzoate or $N$-carbamylglutamate administration. The patients had mean basal GDH activity (18.3 $\pm 0.9 \mathrm{nmol} / \mathrm{min} / \mathrm{mg}$ protein) not different from controls (17.9 \pm $1.8 \mathrm{nmol} / \mathrm{min} / \mathrm{mg}$ protein) in cultured lymphoblasts. The sensitivity of GDH activity to inhibition by guanosine triphosphate was reduced in all patient lymphoblast cultures $\left(\mathrm{IC}_{50}\right.$, or concentrations required for $50 \%$ inhibition of GDH activity, ranging from 140 to $580 \mathrm{nM}$, compared with control $\mathrm{IC}_{50}$ value of $83 \pm$
\end{abstract}

$1.0 \mathrm{nmol} / \mathrm{L}$ ). The allosteric effect of ADP was within the normal range. The activating effect of leucine on GDH activity varied among the patients, with a significant decrease of sensitivity that was correlated with the negative clinical response to a leucinerestricted diet in plasma glucose levels in four patients. Molecular studies were performed in 11 patients. Heterozygous mutations were localized in the antenna region (four patients in exon 11, two patients in exon 12) as well as in the guanosine triphosphate binding site (two patients in exon 6, two patients in exon 7) of the GLUD1 gene. No mutation has been found in one patient after sequencing the exons 5-13 of the gene. (Pediatr Res 50: 353-357, 2001)

\section{Abbreviations:}

HHS, hyperinsulinism and hyperammonemia syndrome

GDH, glutamate dehydrogenase

GLUD1, glutamate dehydrogenase gene

DZX, diazoxide

ID $_{\mathbf{5 0}}$, concentrations required for $50 \%$ inhibition of GDH activity

GTP, guanosine, 5'-triphosphate
Hyperinsulinism is a common cause of recurrent hypoglycemia in early infancy. It is caused by a permanent increase in insulin secretion $(1,2)$. Insulin secretion depends on the ATP/ ADP ratio in $\mathrm{B}$ cells, which causes their depolarization, enhances $\mathrm{Ca}^{2+}$ influx and the exocytosis of insulin. Glucose and leucine regulate insulin secretion by regulating glutaminolysis by glucose (3) and by the direct action of glucose and leucine

Received December 29, 2000; accepted March 18, 2001.

Correspondence: Professeur Jean-Marie Saudubray, Fédération de Pédiatrie, Hôpital Necker-Enfants malades, 149 rue de Sèvres, 75743 Paris cedex 15, France; e-mail: elisabeth.saudubray@nck.ap-hop-paris.fr

Supported, in part, by grants from the National Institutes of Health (RR 00240, DK 53012, DK 56268) and the American Diabetes Association [C.S.]. on GDH. GDH is a mitochondrial enzyme that oxidizes glutamate to $\alpha$-ketoglutarate using NAD and/or NADP as cofactor $(4-8)$.

A new syndrome associating hyperinsulinism with hyperammonemia, HHS, was recently reported to be a cause of diffuse and moderate hyperinsulinism (9-11). It results in excessive GDH (EC 1.4.1.3) activity resulting from a change in its regulation through decreased sensitivity to inhibition by GTP. It has been suggested that the elevated oxidation of glutamate to $\alpha$-ketoglutarate stimulates insulin secretion by the pancreatic B cell by increasing the ATP/ADP ratio, although this has yet to be tested experimentally. Excessive oxidation of glutamate might decrease the $\mathrm{N}$-acetylglutamate in the liver, an 
essential step in the activation of carbamyl phosphate synthase I. This enzyme catalyzes the first step in the detoxification of ammonia in the urea cycle. The GLUD1 gene was mapped to 10q23.3 (12) and contains 13 exons coding for a 505-amino acid mature enzyme. Mutations causing HHS have been identified in exons 11 and 12 of the GLUD1 gene (amino acid positions 445-454) $(10,13)$. More recently, other mutations have been identified in exons 6 and $10(14,15)$. All the patients studied were heterogeneous for one of these mutations, with a sporadic form of the disease, or a familial disease according to dominant inheritance.

This report describes 12 unrelated patients with HHS caused by abnormal GDH, and gives full details of the clinical and biochemical characteristics of hypoglycemia and hyperammonemia. Our results clearly indicate that hyperinsulinemic hypoglycemia is clinically heterogeneous, with neonatal and infancy-onset hypoglycemia and variable responsiveness to medical and dietetic treatments, confirmed by variable responsiveness of cultured lymphocytes to leucine. Oral carbamylglutamate did not normalize venous blood $\mathrm{NH}_{3}$. Mutations were located both within and outside the GTP-binding site, without any correlation between phenotype and genotype.

\section{PATIENTS AND METHODS}

A series of 175 hyperinsulinemic patients were investigated in our institution over the past $20 \mathrm{y}$. Plasma ammonium concentrations were measured since 1997 in 71 of these patients, 45 neonates, and 26 infants, and hyperammonemia ( $>50$ $\mu \mathrm{M})$ was detected in 12 patients.

The diagnostic criteria for hyperinsulinism and the management of the patients with hyperinsulinism have been described (16). Patients with hyperammonemia were investigated further. Venous plasma glucose and ammonium levels of all patients were determined before and after each meal. The measure- ments were done when they were on a normal protein diet during a period of $72 \mathrm{~h}$, after oral protein $(2 \mathrm{~g} / \mathrm{kg})$ and leucine $(150 \mathrm{mg} / \mathrm{kg})$ loads during a period of $48 \mathrm{~h}$ in four patients, and after a protein- and leucine-restricted diet $(2 \mathrm{~g}$ protein and 200 $\mathrm{mg}$ leucine per meal) during a period of $72 \mathrm{~h}$ in nine patients (Table 1).

Arterial ammonium level was measured at the same time as venous concentration in nine patients.

Four patients underwent a selective pancreatic venous catheterization (patients 1, 2, 4, and 6), under general anesthesia, before we knew about the existence and cause of hyperammonemia. Blood samples were collected from the portal and hepatic veins of patient 1 during pancreatic catheterization, to compare pre- and posthepatic ammonemia (17). This patient was anesthetized with curare to relax skeletal muscle, in the belief that hyperammonemia might be of muscular origin. Urinary urea, plasma amino acids, and urinary organic acids were measured by gas chromatography mass spectrometry.

The patients were given oral carbamylglutamate and sodium benzoate at $0.5 \mathrm{~g} / \mathrm{kg}$, divided into three doses over $3 \mathrm{~d}$. Venous blood glucose and ammonium were measured before each intake of these drugs.

Liver ornithine transcarbamylase, $\mathrm{N}$-acetylglutamate synthetase, and glutamine synthase activities were measured in patients 1 and 5 .

The activity of GDH in lymphoblast homogenates and the effect of added ADP or GTP were determined spectrophotometrically according to the protocol of Stanley et al. (10). GLUD1 cDNA was reversed transcribed from lymphoblast mRNA and amplified by the PCR according to Stanley et al. (10). GLUD1 cDNA was sequenced to search for mutations. Results are the mean \pm SEM of three to five determinations. Statistical comparisons were performed using a nonparametric Mann-Whitney test. A $p$ value $<0.05$ was taken as significant.

Table 1. Clinical characteristics of children with HHS

\begin{tabular}{|c|c|c|c|c|c|c|c|c|c|c|c|c|}
\hline \multirow{2}{*}{$\begin{array}{c}\text { Clinical } \\
\text { characteristic }\end{array}$} & \multicolumn{12}{|c|}{ Patient no. } \\
\hline & 1 & 2 & 3 & 4 & 5 & 6 & 7 & 8 & 9 & 10 & 11 & 12 \\
\hline Sex & $\mathrm{M}$ & $\mathrm{F}$ & $\mathrm{M}$ & $\mathrm{F}$ & $\mathrm{M}$ & $\mathrm{F}$ & $\mathrm{F}$ & $\mathrm{M}$ & M & $\mathrm{F}$ & $\mathrm{M}$ & $\mathrm{F}$ \\
\hline $\begin{array}{l}\text { Age at onset of } \\
\text { hypoglycemia }\end{array}$ & $<72 \mathrm{~h}$ & $<72 \mathrm{~h}$ & $<72 \mathrm{~h}$ & $<72 \mathrm{~h}$ & $8 \mathrm{mo}$ & $7 \mathrm{mo}$ & $3 \mathrm{mo}$ & $2 \mathrm{mo}$ & $3 \mathrm{mo}$ & $5 \mathrm{mo}$ & $3 \mathrm{mo}$ & $5 \mathrm{mo}$ \\
\hline $\begin{array}{l}\text { Glucose infusion } \\
\text { rate } \\
(\mathrm{mg} / \mathrm{kg} / \mathrm{min})\end{array}$ & 11 & 7 & 12 & 13 & - & 9 & 15 & 12 & 13 & 12 & - & 12 \\
\hline $\begin{array}{l}\text { Diazoxide } \\
\text { responsiveness }\end{array}$ & \pm & + & \pm & + & + & - & + & \pm & + & + & + & + \\
\hline $\begin{array}{l}\text { Leucine-restricted } \\
\text { diet } \\
\text { responsiveness }\end{array}$ & + & ND & - & + & + & + & - & - & ND & + & - & ND \\
\hline Oral leucine load & $\mathrm{H}$ & ND & ND & $\mathrm{H}$ & $\mathrm{H}$ & ND & ND & ND & ND & $\mathrm{H}$ & ND & ND \\
\hline Present age (y) & 6 & 13 & 2 & 6 & 13 & 3 & 2 & 3 & 5 & 7 & 2 & 4.5 \\
\hline
\end{tabular}

Oral diazoxide was administered at $15 \mathrm{mg} / \mathrm{kg} / \mathrm{d}$ divided into three doses. Diazoxide efficacy was defined as blood glucose levels $>3 \mathrm{mmol} / \mathrm{L}$, before and after each meal in patients fed normally with a physiological overnight fast, after i.v. glucose and any other medications had been stopped for at least five consecutive days. M, male; F, female; ND, not determined; H, hypoglycemia; DZX, diazoxide; Corn, cornstarch; Leucine, leucine-restricted diet. 
These studies were approved by the local ethics committees and written informed consent was obtained from the parents.

\section{RESULTS}

Hyperinsulinemic hypoglycemia. The clinical characteristics of the patients with HHS are summarized in Table 1. All patients (six males and six females) except one (patient 11) had unrelated parents. The maternal aunt of patient 1 had suffered from hyperinsulinism during infancy. The mother of patient 6 had suffered from leucine-sensitive hypoglycemia, diagnosed at the age of $11 \mathrm{mo}$. She was treated by a low-protein diet until she was 9 y old, when she was thought to have recovered spontaneously. Her intellectual development is presently normal. The other patients had no family history of hypoglycemia. The father of patient 2 died from a pancreatic carcinoma at the age of $43 \mathrm{y}$, without any previous hypoglycemia.

All patients were born at full term and only four patients were macrosomic at birth (Table 1). Hypoglycemia began within the first $3 \mathrm{~d}$ of life in four cases and later in infancy in the other cases. Seizure was the presenting symptom of hypoglycemia in most patients. Ten patients required continuous oral or i.v. glucose to keep their plasma glucose $>3 \mathrm{mmol} / \mathrm{L}$. However, the mean rate of glucose administration was only $11.7 \mathrm{mg} / \mathrm{kg} / \mathrm{min}$ and no patient required i.v. glucagon in addition to glucose. Nine patients were fully sensitive to diazoxide, one was diazoxide-resistant (patient 6), and two others required cornstarch in addition to diazoxide (patients 1 and 8). A leucine-restricted diet $(200 \mathrm{mg} / \mathrm{meal})$ adequately controlled hypoglycemia in five cases (patients 1, 4, 5, 6, 10), maintaining the plasma glucose $>3 \mathrm{mmol} / \mathrm{L}$ while patients were fed at normal intervals, and received no i.v. glucose or any other medication for at least five consecutive days. It was ineffective in four cases (patients $3,7,8,11$ ). Among patients who were sensitive to a leucine-restricted diet, four were given an oral leucine load and suffered from hypoglycemia with hyperinsulinemia $1 \mathrm{~h}$ after the load. No oral leucine load was given to the latter patients because of the potential risk of severe hypoglycemia.

Overall, all but one patient (patient 6) were successfully treated medically, using diazoxide, a leucine-restricted diet, and/or cornstarch. Patient 6 , who was diagnosed before the HHS was described, underwent a pancreatic resection including the tail and half the body of the pancreas. The preoperative pancreatic venous catheterization had shown high insulin levels throughout the pancreas. His histopathological study confirmed that the hyperinsulinism was diffuse, but the lesion was unusual with hypertrophic islet cells arranged in ribbon patterns. The patient still had hypoglycemia after surgery, but was successfully treated by a leucine-restricted diet. The three other patients (patients 1,2, and 10) who underwent pancreatic catheterization also displayed diffuse insulin secretion throughout the pancreas, and they were not operated on.

Hyperammonemia and metabolic investigations. Hyperammonemia was discovered before hypoglycemia in patients 1 and 5, whereas it was detected retrospectively in the other patients, who had been previously diagnosed with hyperinsu- linism. The characteristics of hyperammonemia are summarized in Table 2.

The venous plasma ammonia concentration was slightly increased in all patients $(90-200 \mu \mathrm{mol} / \mathrm{L}$, normal $<50$ $\mu \mathrm{mol} / \mathrm{L})$ and in the mother of patient $6(90 \mu \mathrm{mol} / \mathrm{L})$. All other parents tested had normal ammonia concentrations. Hyperammonemia was not influenced by oral protein load (patients 1 , 5), low-protein and low-leucine diets (patients 1, 3-8, 10, 11), sodium benzoate (patients $1,2,5$ ), or $N$-carbamylglutamate (patients 1-3, 5, 6, 8, 11).

The arterial blood ammonia concentration was increased $(>50 \mu \mathrm{mol} / \mathrm{L})$ in all the patients investigated, except patient 1 (arterial ammonia $36-40 \mu \mathrm{mol} / \mathrm{L}$, peripheral venous ammonemia $150 \mu \mathrm{mol} / \mathrm{L}$ ). This patient had elevated ammonia concentrations in the portal vein $(111-132 \mu \mathrm{mol} / \mathrm{L})$ but normal values in the subhepatic veins $(38-41 \mu \mathrm{mol} / \mathrm{L})$ during pancreatic catheterization (17).

Plasma glutamine and urinary alpha ketoglutarate concentrations varied (Table 2), whereas plasma arginine, urinary urea, and orotic acid concentrations were normal in all patients investigated. Hepatic ornithine transcarbamylase and $\mathrm{N}$ acetylglutamate synthase (patients 1 and 5) and glutamine synthase (patient 1) activities were normal.

Glutamate dehydrogenase. The activity and allosteric responses of GDH in lymphoblasts from 10 of the 12 patients are shown in Table 2. All the patients investigated had normal basal GDH activities. The $\mathrm{IC}_{50}$ of GTP was $70-600 \%$ higher than that of controls, consistent with an excessive activity of GDH (Fig. 1). The allosteric effect of activation by ADP was normal. The effect of $1 \mathrm{mM}$ leucine on GDH activity varied among the patients (Fig. 2). There was a significant decrease in GDH sensitivity to activation by leucine in patients $4,7,8$, and 10.

Molecular analysis of the GDH gene showed that four patients were heterozygous for a missense mutation within exon 11 (patients $1,8,9,11$ ) and two within exon 12 in the antenna region of the enzyme (patients 3,12) (Table 2). Four other patients (patients 1,5-7) had a heterozygous mutation in exons 6 and 7 in the GTP-binding site (18). No mutation has so far been found for patient 10 , after sequencing the exons 5-13 of the gene. Most studied patients had one mutant and one wild-type allele, consistent with the dominant expression of the mutations. Samples from the parents of patients were not available for mutation analysis.

\section{DISCUSSION}

We report here the features of 12 patients with HHS. Ten of these patients who underwent enzymatic and molecular investigations had abnormal glutamate dehydrogenase activity, supporting the concept that a GDH alteration is the cause of HHS. According to Stanley et al. (1), and at odds with Yorifuji et al. (14), the sensitivity of GDH enzyme to inhibition by GTP was reduced although its basal activity was normal, which is consistent with its overactivity in vivo. Heterozygous mutations in the GLUD1 gene were found in all but one patient. These mutations were located in the antenna region of the enzyme in six patients and in the GTP-binding site in four patients. 


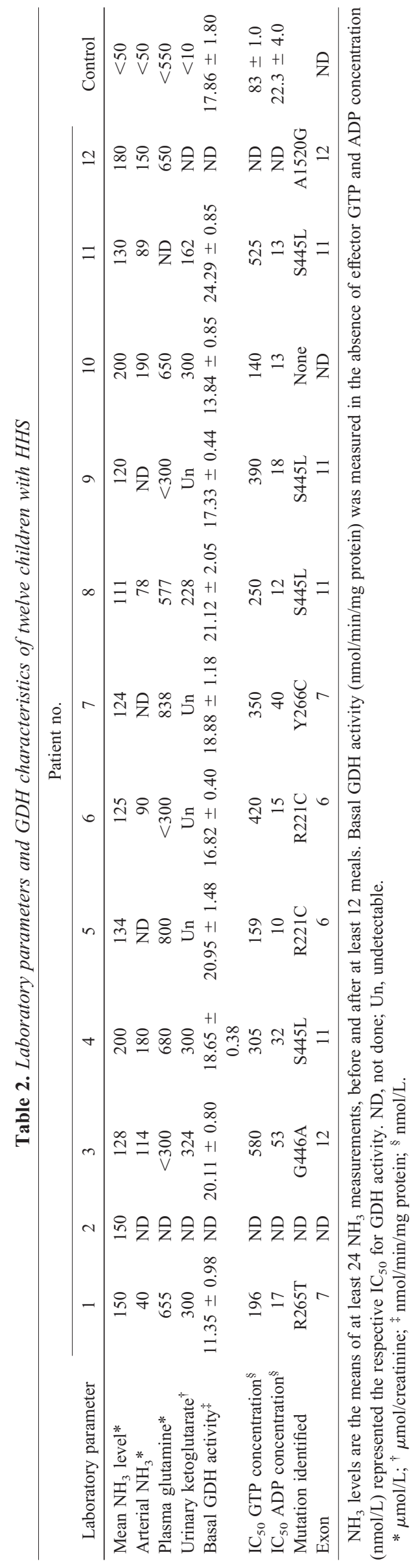

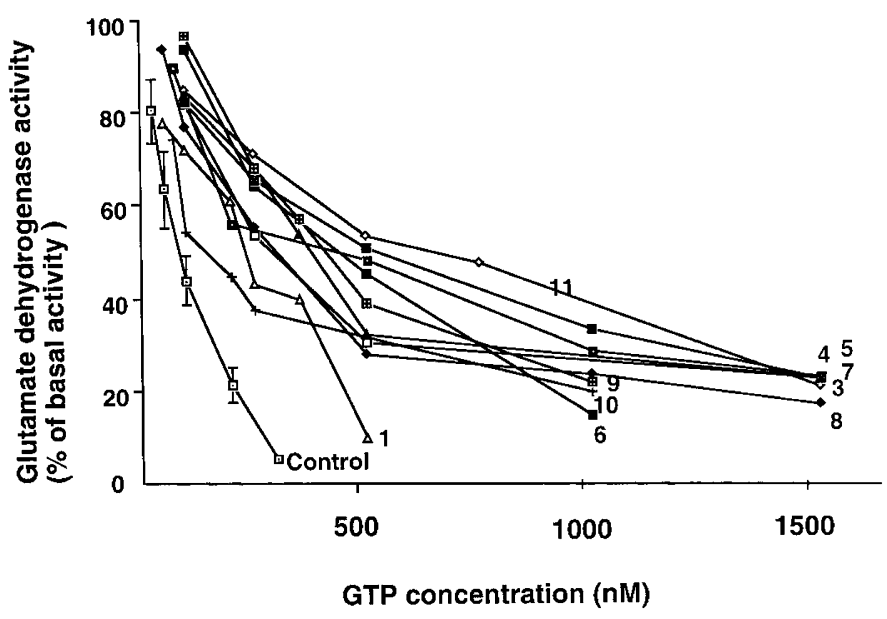

Figure 1. Effects of GTP on GDH activity in lymphoblasts from patients with HHS and normal subjects. Basal GDH activities for patients $(n=10)$ and controls $(n=9)$, expressed as $\mathrm{nmol} / \mathrm{min} / \mathrm{mg}$ protein, are indicated in Table 2. $\mathrm{ID}_{50}$ were determined graphically and are shown in Table 2.

Mutations in the GTP-binding site encoded by exons 6 and 7 have also been described by Miki et al. (15) and Santer et al. (19). No phenotype-genotype correlation was found according to the location of the mutations (15). Mutations in both the GTP-binding and antenna regions were associated with neonatal and infancy-onset of hypoglycemia, as well as with variable responsiveness to diazoxide. In the same way, comparable overactivity of GDH was found in subjects with both locations of mutations.

Although leucine directly regulates insulin secretion by acting on a separate leucine-binding allosteric site on GDH (8), surprisingly, the effect of $1 \mathrm{mM}$ leucine on lymphoblast GDH activity varied among the patients (Fig. 2). Lymphoblast GDH activity in patients $4,7,8$, and 10 decreased in response to leucine. The mutations on the GLUD1 gene of these patients were located on exons 11 and 12, as well as exons 6 and 7 .

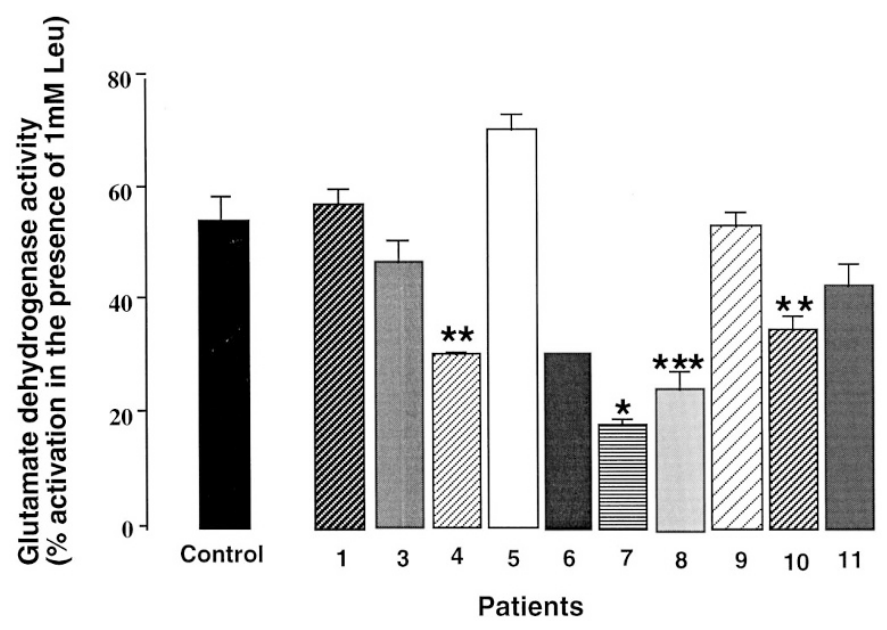

Figure 2. Effect of $1 \mathrm{mM}$ leucine on GDH activity in lymphoblasts from patients with HHS and control subjects. Results, expressed as percentage of activation of basal activity, are the means \pm SEM of three to six experiments. $* p<0.02 ; * * p<0.01 ; * * *<0.002$. 
These findings do not support the concept that a leucinerestricted diet is constantly effective on plasma glucose levels in $\operatorname{HHS}(9,20,21)$.

Whereas hypoglycemia is the result of the increased B-cell ATP/ADP ratio by decreasing sensitivity to allosteric inhibition of GDH to GTP, the mechanism of hyperammonemia is not clear yet. All the patients investigated had normal urinary urea excretion and urea cycle enzyme activities. In the same way, venous ammonia did not depend on dietary protein intake and did not decrease in response to sodium benzoate, suggesting that ammonia was detoxified by the liver. More interestingly, $N$-carbamylglutamate, an analog of $N$-acetylglutamate, the natural allosteric activator of the urea cycle, did not normalize venous ammonia in any patient, which argues against the hypothesis that hyperammonemia is caused by decreased $\mathrm{N}$-acetylglutamate synthesis by the liver. Finally, in patient 1 , who has a GLUD1 mutation in exon 7, peripheral venous blood ammonia levels were normalized during curarization and his arterial ammonia was normal. This suggests that muscle relaxation decreased the circulating ammonia concentration and that hyperammonemia could have a peripheral muscular origin (17).

The diagnosis of patients with HHS is crucial; $30 \%$ of the infants tested and half the neonates who were sensitive to diazoxide in our series had HHS, and their therapy differs radically from that of other hyperinsulinemic patients. The hypoglycemia in HHS is less severe than in the forms of hyperinsulinism associated with SUR1 or Kir6.2 mutations (focal or diffuse), which usually require high rates of i.v. glucose and pancreatic surgery, and the treatment is much easier, particularly in neonates (16). All but one of our HHS patients had at least a partial response to diazoxide $(9,22)$, in agreement with the fact that the diazoxide-binding site is located in the inward-rectifying potassium-channel (Kir6.2). Surprisingly, one patient was resistant to diazoxide, which differed from the results of other medically treated patients $(9$, 22). Half of them were sensitive to a leucine-restricted diet. These possibilities of a medical treatment and the possible improvement over time in patient 5 and in the mother of patient 6 support a conservative approach to management for patients with HHS. Together with the fact that these patients have diffuse pancreatic disease, this suggests that invasive investigations, such as transhepatic pancreatic catheterization, are contraindicated in HHS patients.

In conclusion, the serum ammonia concentration should be measured in each patient investigated for hyperinsulinism because the treatment, follow-up, and genetic counseling differ radically. Conversely, hypoglycemia should be looked for in patients with hyperammonemia of uncertain etiology. The question of whether moderate hyperinsulinism without hyperammonemia could be the result of GDH abnormality, as recently described by Santer et al. (19), remains to be clarified, particularly in patients who have leucine-sensitive hyperinsu- linism. Finally, if the consequences of GDH mutation on glucose metabolism are clearly related to an inappropriate insulin secretion, the consequences of GDH mutation on ammonemia metabolism are not clear yet.

Acknowledgments. We thank Dr. Betty Y.L. Hsu and technicians Courney B. MacMullen and Karen Kutoloski, Dr. Recan, Dr. Nivot, Dr. Le Touzet, Dr. Fournet, Dr. Rahier, and Prof. Junien.

\section{REFERENCES}

1. Stanley C 1997 Hyperinsulinism in infants and children. Pediatr Clin North Am 44:363-74

2. Bruining GJ 1990 Recent advances in hyperinsulinism and the pathogenesis of diabetes mellitus. Curr Opin Pediatr 2:758-765

3. Gao ZY, Li G, Najafi H, Wolf BA, Matschinsky FM 1999 Glucose regulation of glutaminolysis and its role in insulin secretion. Diabetes 48:1535-1542

4. Sener A, Malaisse WJ 1980 L-leucine and a nonmetabolized analogue activate pancreatic islet glutamate dehydrogenase. Nature 288:187-189

5. Sener A, Malaisse-Lagae F, Malaisse WJ 1981 Stimulation of pancreatic islet metabolism and insulin release by a nonmetabolizable amino acid. Proc Natl Acad Sci U S A 78:5460-5464

6. Knudsen P, Kofod H, Lernmark A, Hedeskov CJ 1983 L-leucine methyl ester stimulates insulin secretion and islet glutamate dehydrogenase. Am J Physiol 245:E338-E3446

7. Fahien LA, MacDonald MJ, Kmiotek EH, Mertz RJ, Fahien CM 1988 Regulation of insulin release by factors that also modify glutamate dehydrogenase. J Biol Chem 263:13610-13614

8. Peterson P, Smith TJ 1999 The structure of bovine glutamate dehydrogenase provides insight into the mechanism of allostery. Structure 7:769-782

9. Zammarchi E, Filippi L, Novembre E, Donati MA 1996 Biochemical evaluation of a patient with a familial form of leucine-sensitive hypoglycemia and concomitant hyperammonemia. Metabolism 45:957-960

10. Stanley CA, Lieu YK, Hsu BYL, Burlina AB, Greenberg CR, Hopwood NJ, Perlman K, Rich BH, Zammarchi E, Poncz M 1998 Hyperinsulinism and hyperammonemia in infants with regulatory mutations of the glutamate dehydrogenase gene. N Engl J Med $338: 1352-1357$

11. Weinzimer SA, Stanley CA, Berry GT, Yudkoff M, Tuchman M, Thornton PS 1997 A syndrome of congenital hyperinsulinism and hyperammonemia. J Pediatr 130:661664

12. Deloukas P, Dauwerse JG, Moschonas NK, van Ommen GJ, van Loon AP 1993 Three human glutamate dehydrogenase genes (GLUD1, GLUDP2, and GLUDP3) are located on chromosome 10q, but are not closely physically linked. Genomics 17:676681

13. Stanley CA, Fang Jie, Kutyna K, Hsu BYL, Ming JE, Glaser B, Poncz M 2000 Molecular basis and characterization of the hyperinsulinism/hyperammonemia syndrome. Diabetes 49:667-673

14. Yorifuji T, Muroi J, Uematsu A, Hiramatsu H, Momoi T 1999 Hyperinsulinismhyperammonemia syndrome caused by mutant glutamate dehydrogenase accompanied by novel enzyme kinetics. Hum Genet 104:476-479

15. Miki Y, Taki T, Ohura T, Kato H, Yanagisawa M, Hayashi Y 2000 Novel missense mutations in the glutamate dehydrogenase gene in the congenital hyperinsulinismhyperammonemia syndrome. J Pediatr 136:69-72

16. de Lonlay-Debeney P, Poggi-Travert F, Fournet JC, Sempoux C, Dionisi-Vici C, Brunelle F, Touati G, Junien C, Nihoul-Fékété C, Robert JJ, Saudubray JM 1999 Clinical features of 52 neonates with hyperinsulinism. N Engl J Med 340:1169-1175

17. Kamoun P, Rabier D, Saudubray JM 1998 Muscular origin of hyperammonemia. Eur J Pediatr 157:868

18. MacMullen C, Fang J, Hsu BYL, Kelly A, de Lonlay-Debeney P, Saudubray JM, Ganguly A, Smith TJ, Stanley C 2001 Hyperinsulinism/Hyperammonemia Syndrome in Children with Regulatory Mutations in the Inhibitory Guanosine TriphosphateBinding Domain of Glutamate Dehydrogenase. J Clin Endocrinol Metab 86:17821787

19. Santer R, Schneffenheim R, Kinner M, Passarge M, Supertifuga A, Schaub J 2000 Glutamate dehydrogenase gene (GLUD1) mutations: novel mechanisms leading to congenital hyperinsulinism. J Inherit Metab Dis 23(Suppl):176

20. Zuniga O, Golden MP, Sargeant DT, Graham MJ, Bradvica C, Santiago J, White NH 1983 Persistent leucine sensitivity following partial pancreatectomy and diazoxide treatment. Am J Dis Child 137:393-395

21. Roe TF, Kogut MD 1982 Idiopathic leucine-sensitive hypoglycemia syndrome: insulin and glucagon responses and effects of diazoxide. Pediatr Res 16:1-4

22. Huijmans JG, Duran M, de Klerk JB, Rovers MJ, Scholte HR 2000 Functional hyperactivity of hepatic glutamate dehydrogenase as a cause of the hyperinsulinism/ hyperammonemia syndrome: effect of treatment. Pediatrics 106:596-600 